\title{
DIE UITGEBRANDE VERSKYNSEL IN DIE MODERNE BEROEPSMENS
}

\section{FREDRIKA M J DE VILLIERS \\ Departement Verpleegkunde, Potchefstroomse Universiteit vir $\mathrm{CHO}$}

\section{SUMMARY}

\begin{abstract}
The author is of the opinion that the changes in the modern world have contributed to the development of the burn-out phenomenon.

Burn-out is characterised by physical, emotional and spiritual exhaustion which affects a person's working as well as personal life. Certain people are more susceptable than others, including dynamic personalities, those in the service professions, the modern woman and the middle-aged.

At personal and management level there should be an awareness of the causes, signs and symptoms and consequences of burn-out. Once the problem is diagnosed steps can be taken to deal with it.
\end{abstract}

\section{RELIËF}

Ons kan onsself dié vraag stel: waarom het so baie mans en vrouens die $\sin$ van hulle lewe verloor? Hulle entoesiasme is weg. Hulle voel onbetrokke, selfs te midde van hulle gesinne en vriende. Hulle ervaar ' $n$ toenemende ontevredenheid en pessimisme. Hulle is liggaamlik en geestelik uitgeput, hulle is chronies moeg en energieloos. Hulle beroep, wat soveel beteken het, het 'n swaar las geword met geen gevoelens van beloning en waardering wat daarmee gepaard gaan nie. Of dit ook al in ouerskap, studie, liefde, huwelik of werk is die mense het aanvanklik met hoë verwagtings en visies van sukses begin. Die grootste deel van hul lewe was hulle entoesiasties, energiek en optimisties, maar geleidelik het afstomping, verveling en wanhoop ingetree (Freudenberger, 1980: 1-3).

Ons leef ongetwyfeld in 'n tydvak van ingrypende en snelle veranderinge. Ons het moontlik in die afgelope dekades, van die Tweede Wêreldoorlog af, seker groter veranderinge gesien as gedurende die res van die geskiedenis. Tegnologie het ons gebombardeer met nuwe maniere om dinge te doen en welvaart het vir ons meer vrye tyd gebring as wat ons kan hanteer. Kredietkaarte stimuleer en vergemaklik ons koopvermoë. Onderwys het ons op nuwe plato's (niveaus) geplaas wat ons onvergenoegd maak met 'n eenvoudige lewenstyl (Ibid.: 3). Deur groter kommunikasie bring die radio, televisie, koerant, vermaaklikheidswêreld, wetenskaplike handboeke en oor en weer reise mee dat geen gemeenskap meer geïsoleerd bestaan nie. Hierdie kennismaking met ander kulture, normsisteme, lewensbeskouings en tradisies lei ook tot die bevraagtekening van die geldigheid van jou eie (Duvenage. Referaat: 2 -3 ).

Gepaard hiermee ervaar die hedendaagse samelewing 'n geweldige verskuiwing in die normsisteem. Vergelyk byvoorbeeld die seksuele revolusie wat 'n drastiese transformasie teweeggebring het met die sogenaamde vrye liefde, saamwonery of die sogenaamde proefhuwelike, egskeidings, wat 'n mode geword het en die vrou wat haar rol herdefinieer (Freudenberger, 1980: $3-4$ ).

In die verband moet veral melding gemaak word van die ontkersteningsproses wat in die Weste aan die gang is en wat direk invloed uitoefen op die begronding van verantwoordelikheid as respons tot Bybelse beginsels en norme. Die mens is vasgevang tussen twee botsende kulture (Duvenage: referaat 2).

In ons poging om met al die veranderinge tred te hou, stel ons geweldige eise aan onsself. Om ons posisie te handhaaf, moet ons onsself voortdurend versnel en harder probeer. Sodoende brand ons ons- self uit. As ons ons doel bereik het, vind ons min vreugde daarin, ons is te moeg om dit te waardeer. Dikwels eindig ons pogings in frustrasie en teleurstellings, ons houdings in sinisme. Die vitale vonk in ons lewens brand uit en laat 'n wrak agter. Vergelyk maar 'n uitgebrande huis of motor (Freudenberger, 1980: $5-6$ ).

Die skrywer is van mening dat hierdie klimaat die voedingsbodem vir die ontstaan van die uitgebrande verskynsel is.

\section{WAT IS DIE UITGEBRANDE VERSKYNSEL}

Alhoewel die intensiteit, duur, frekwensie en gevolge van mens tot mens varieer, word tussen drie basiese komponente in die uitgebrande verskynsel onderskei, naamlik fisiese, emosionele en geestelike uitputting (Pines et. al. 1981:17).

\section{Fisiese uitputting}

Fisiese uitputting word gekenmerk deur 'n lae energievlak, chroniese uitputting, swakheid en matheid. Algemene klagtes is spanningshoofpyn, pyn in die nek of rug, veranderende eetgewoontes - oormassa, verlaagde weerstand teen siektes, maklike opdoen van virusgriep en verkoues, slaaploosheid en slegte spysvertering.

Baie poog om hulle matheid deur middel van alkohol, rook en kal- 
meermiddels te oorwin. Hierdie maatreëls bring net tydelike verligting, laat die individu dikwels met 'n oorweldigende gevoel van tamheid en wanhoop.

\section{Emosionele uitputting}

Emosionele uitputting omsluit gevoelens van terneergedruktheid, hulpeloosheid en hopeloosheid wat in ekstreme gevalle selfs tot geestesiekte en gedagtes van selfmoord lei. Hulle emosionele bronne is gedreineer, hulle beste vriende irriteer hulle, hulle ken nie hulle vrou/man of kinders nie. Hulle het nie die emosionele energie om vriendelik, hartlik of verdraagsaam te wees nie. Dikwels verval hulle in selfbejammering en wil net alleen gelaat word, en is ook senuagtig. Selfs die gesinslede, familie, en vriende is nie meer 'n bron van ondersteuning nie, hulle stel nog net verdere eise. Nutteloosheid en wanhopigheid neem toe. Bevrediging deur werk en ander aktiwiteite verdwyn. Gevoelens van vreugde en hoop word vervang deur eensaamheid, ontmoediging en ontnugtering. Dikwels hoor ons: ék voel só dood

\section{Geestelike uitputting}

Geestelike uitputting word gekenmerk deur die ontwikkeling by die persoon van negatiewe houdings en gesindhede ten opsigte van homself, sy medemens, sy werk, die lewe en sy God. Daar is onvergenoegdheid ten opsigte van sy werk en sy lewenstyl, en 'n swak selfbeeld. Sulke mense voel onbekwaam, minderwaardig en onbevoegd. Hulle voel waardeloos, 'n totale mislukking en pessimisties en is koud en onpersoonlik in hulle menslike verhoudinge. Hulle ontwikkel 'n dehumaniserende (onpersoonlike) houding ten opsigte van die aan wie hulle diens lewer. Die persoon wat ander dehumaniseer ervaar minder emosies, minder empatie, en minder persoonlike gevoelens en dehumaniseer homself dus in die proses. Uitgebrande professionele mense sien kliënte of pasiënte nie as individue nie maar as probleme.

Navorsing toon dat verpleegkundiges wat in intensiewe eenhede werk, meer onverdraagsaam, depressief, ernstig en vyandig is as dié wat in algemene sale werk.

Die mense soek nie na roepingsvervulling nie, dikwels is dit net die sekuriteit en geld wat goed is. Hulle ervaar ook ' $n$ vertroebeling in hulle verhoudinge met kollegas, gesinslewe, dra dikwels by tot huwelikspanninge en konflikte en hulle stel hoër eise aan die gesinslede (ibid, 19-21)

Dit is belangrik om die gevaartekens en simptome betyds te herken en erken. Wanneer al bogenoemde ervaar word, is u alreeds in 'n uitgebrande krisis. Net 'n paar van die genoemde tekens is waarskuwende tekens. Dan is dit tyd om u prioriteite by die werk en die huis te ondersoek. Die spanninge ontspring uit die genoemde omgewings en hoe dit die mens beïnvloed hang af van die doeltreffendheid van die mens se spanningshanteringstyl of strategieë. Dit verskil van mens tot mens, dit kan 'n paar dae, maande of jare duur. Soms kan spanning voorkom ten opsigte van die gesin en tog vind ons bevrediging in die werk of andersom.

Dit is ook belangrik om te onthou dat die gevaartekens ook in ander gesien kan word, byvoorbeeld by werkers of kollegas, met ander woorde die uitgebrande verskynsel is nooit 'n geheim nie.

\section{WIE IS DIE POTENSIEEL UIT- GEBRANDE PERSOON?}

Dit is nie elke mens wat vatbaar is vir uitbranding nie en sekere persone is potensieel meer vatbaar.

\section{Dinamiese persoonlikhede}

Die persone wat ten prooi val, is meestal individue met dinamiese, charismatiese eienskappe wat hard strewe om 'n doel te bereik, wat besige skedules het, en meer as hulle deel in enige projek doen. Hulle is gewoonlik leiers wat nie in staat is om hulle beperkinge te herken nie. Hulle het hulself te hard en te lank gedryf. Hulle begin met 'n ideaal - wat moontlik hul huwelik, kinders, posisie, geld, mag beroep/professie kan wees - wat nie daarin geslaag het om die verwagte beloning te verwesenlik nie (Freudenberger, 1980: $11-12-$ 13).
Persone wat diens lewer aan hul medemens

Persone wat kies om hul diens te wy aan hulle medemens, byvoorbeeld in die gesondheidsdienste, maatskaplike werk en onderwys kan potensieel uitgebrand raak. Hulle beskik almal oor drie basiese eienskappe:

- hulle lewer emosioneel belasbare werk;

- hulle beskik oor bepaalde persoonlikheidseienskappe, 'n groter sensitiwiteit teenoor hulle medemens en 'n groot mate van empatie vir die lyding van ander;

- hulle het 'n kliënt-gesentreerde oriëntasie.

Die fokus is op die mense wat die diens ontvang. Die professionele persoon se rol van hulpverlening, begrip en ondersteuning word bepaal deur die kliënt se behoeftes. Die meeste menslike verhoudinge is simmetries maar nie die terapeutiese verhouding nie, dit is komplimenterend - die professionele persoon gee en die kliënt ontvang.

In die wetenskaplike literatuur en kurrikulae relevant aan die medemens-diens veld word min aandag bestee aan die emosionele spanninge wat deur die professionele persone ervaar word. In plaas daarvan is die fokus hoofsaaklik op die ontvangers van die dienste en hulle probleme gerig. Tradisioneel word daar net gekonsentreer op kognitiewe materiaal en min of geen aandag word aan die ontwikkeling van vaardighede in die hantering van mense of die emosionele spanninge wat deur die mense ervaar word, gegee nie.

Marlene Kramer, 'n professor in verpleegkunde skryf in haar boek Reality shock (1974) oor die geweldige uitwerking wat verpleging op die jong en onervare verpleegster het. Werklikheidskok lei dikwels tot 'n induksiekrisis wat weer tot verlies van studente, veral gedurende die eerste paar maande van verpleging, kan aanleiding gee.

In hulle strewe om nie oorbetrokke te raak by die kliënt of pasiënt se probleme en lyding nie, ontstaan daar die gevaar van totale distansiëring wat gekenmerk word deur die verlies van besorgdheid en die dehumaniserende houdinge wat 
so kenmerkend van die uitgebrande professionele werker is. Met hierdie oormatige distansiëring is daar nie voldoende betrokkenheid om doeltreffende hulp en ondersteuning te verleen nie. Diegene wat besig is om uit te brand, onttrek hulle fisies, sosiaal, emosioneel en geestelik. Daarom sal geneeshere en verpleegsters wat uitgebrand is tydens pasiënte se gesprekke oor hul probleme intellektualiseer en rasionaliseer en meer tegnies word. Hulle primêre besorgdheid word die siekte en nie die pasiënt nie. Hulle gebruik hierdie onttrekking om die intensiteit van die emosioneelwekkende, inherent in hul beroepe, te verminder (Pines, et. al. 1981: 4561).

\section{Die moderne vrou}

Die toenemende invloed van die vroue-vryheidsbeweging en die veranderende rol van die vrou lei tot uitbranding. Meer vrouens kies 'n beroep as essensiële deel van hulle lewe wat 'n bydraende faktor tot uitbranding geword het. Dit is duidelik dat die moderne vrou gekonfronteer word met die antreklikheid, moontlikheid en noodsaaklikheid van beroepsarbeid aan die een kant en haar onmiskenbare teenwoordigheid in gesinsverband aan die ander kant. Anders as in die geval van die man, kan die getroude vrou se beroepswerk nooit van haar gesinsituasie losstaan nie.

Hieruit ontstaan haar problematiek of rolkonflik. Dit is ' $n$ byna onoplosbare dilemma wat van haar 'n burgeres van twee wêrelde maak. Dit dra by tot spanning en vermoeienis. Ten einde hierdie konflik te vermy, verkies baie vroue om nie kinders te hê nie, vandaar so 'n groot daling in die kindergeboortesyfer in die Westerse wêreld. Ander weer, kies 'n deeltydse werk, (dit word meer algemeen), hulle verkies om 'n gesin te hê en vind ook die beroepswerk meer hanteerbaar. Die meer professionele vroue sien hul werk nie as regverdiging om minder by die huis te doen, soos met die meeste mans gebeur nie. Hulle koester hoë verwagtings van hulself en sien hulself as ' $n$ super professionele vrou wat noodwendig 'n supermoeder en supertuisteskepper ook moet wees. Hulle betaal duur vir hierdie keuse; die konflik, frustrasie, angs en skuldgevoelens dra by tot liggaamlike, emosionele en geestelike vermoeidheid wat uiteindelik tot uitbranding lei.

Die moderne vrou kan dus of 'n oorbelaste uitgebrande beroepsvrou en moeder wees of 'n gelukkige en selfvervullende beroepsvrou en moeder.

Die teenoorgestelde is ook waar van die vrou wat kies om nie beroepsarbeid te verrig nie. Daar is die huisvrou wat haar tradisionele en eeue-oue roeping as haar plig en voorreg sien. Daar is ook die huisvrouens wat die neurotiese-huisvrou-sindroom vertoon. Hulle is chronies moeg en emosioneel gedreineer en geïrriteerd. Hulle voel gevange, terneergedruk en negatief. Baie van hulle is uitgebrand in hulle rolle as vrou en moeder en is dikwels twisgierig en sien hul taak as 'n las en 'n kruis (Pines et. al., 1981 82 - 99).

\section{Die middeljarekrisis}

Die middeljarekrisis en sy korrelaat middelberoepskrisis is ' $n$ fase in volwasse ontwikkeling wat tans skerp onder die soeklig staan. Die ouderdom tussen 40 en 50 jaar is 'n periode van herwaardering van jouself, jou lewe en jou beroep. Dit gaan dikwels gepaard met gevoelens van leegheid, ontnugtering en diepe wanhoop. Daar is 'n pynlike bewustheid van jou eie mortaliteit, die snelverbygaande tyd en die tyd wat nog oor is. Simptome van die middeljare korreleer in ' $n$ groot mate met die uitgebrande verskynsel. Ons sien mans en vrouens in hulle middeljare wat dikwels professionaliste in die hoogste bestuursposte is wat werkverslaafdes was, wat hulle gesins- en sosiale lewe opgeoffer het in belang van hulle ambisie, wat uitbrand midde in hulle beroep en wat die sin en waarde van hulle lewe begin bevraagteken in die besef van die hoë prys wat hulle vir hul sukses moes betaal (Pines, et al., 1981: 174 176).

\section{DIE GEVOLGE VAN DIE UIT- GEBRANDE VERSKYNSEL}

Sommige verlaat die beroep na lang jare van opleiding en dit gaan dikwels met 'n gevoel van mislukking, skuldgevoelens en 'n mors van tyd gepaard. Dit is nie net 'n onkoste en verlies vir die organisasie nie, maar ook vir die samelewing as geheel.

Ander verlaat net hulle spesifieke werk, maar bly òf in die professie of in dieselfde organisasie. Dikwels vind hulle ten opsigte van die verandering van werk dieselfde probleme in die nuwe werk. Dikwels nadat hulle in 'n reeks verskillende werke uitgebrand het, ontwikkel hulle 'n chroniese gevoel van hopeloosheid en mislukking.

Ander weer sal opwaarts beweeg na 'n bestuurspos as 'n ontvlugting van die werk waarin hulle uitgebrand het, om van direkte kontak met die pasiënt of kliënt verwyder te wees. Oppervlakkig beskou lyk dit na 'n redelike oplossing maar ervaring toon dat niks erger is as juis 'n uitgebrande werker wat nou ander persone moet rig, motiveer en oor hulle moet toesig hou nie. Dikwels is hulle die oorsaak dat die uitgebrande verskynsel onder ander werkers toeneem.

Daar is ook diegene wat nooit hul werk verlaat nie. Hierdie mense word gewoonlik gemotiveer deur ' $n$ behoefte aan sekuriteit en as hulle 'n permanente werk moet aanvaar en aftreevoordele verkry dan bly hulle aan as dooie hout.

Hulle doen so min as moontlik en reageer meestal op navrae met: ek weet nie, ek werk net hier. Hulle verloor hulle motivering vir verandering en vernuwing, en selfs wanneer hulle 'n meer bevredigende posisie aangebied word, wys hulle dit van die hand (Pines, 1981: 22 23).

\section{IS U BESIG OM UIT TE BRAND?}

Wanneer u terugkyk op die afgelope ses maande - het $u$ veranderinge in uself en die wêreld om u waargeneem? Dink aan die kantoor, of $u$ werksituasie, u gesin en sosiale lewe. Voel u miskien meer moeg as energiek? Werk u al harder en bereik al minder? Is u meer sinies en meer ontnugterd? Word u dikwels oorval deur 'n gevoel van onverklaarbare neerslagtigheid en hartseer? Raak u meer vergeetagtig? Is u meer geïrriteerd, kortgebonde, meer teleurgestel in mense om $u$ ? Sien u u vriende en familie minder dikwels? Is u te besig om gewone roetinedinge te doen? Het u niks vir mense te sê nie? As u op ongeveer die helfte van dié vrae $j a$ 
antwoord is $\mathrm{u}$ besig om uit te brand! Indien $\mathrm{u}$ antwoord op die meeste van die vrae positief is, is $u$ in ' $n$ gevaarsone, wat gevaar vir u liggaamlike, emosionele, sosiale en geestelike welsyn inhou (Freudenberger en Richelson 1980: $17-18$ ).

Dit geld natuurlik ook vir die werkgewer dat hy na die sinjale in sy werkers moet oplet en doelbewus iets daaraan doen.

\section{HANTERING VAN UITBRAN- DING}

Wees bewus van die probleem, die oorsake, tekens en simptome en die gevolge daarvan. Dit help u om 'n diagnose te maak van die situasie waarin u verkeer.

Neem die verantwoordelikheid om iets daaromtrent te doen. Die volgende is 'n paar wenke om uitbranding te hanteer.

- Aanvaar verantwoordelikheid vir u eie gesondheid - liggaam, siel en gees. Luister na u eie liggaam.

- Indien u chronies moeg is, kan dit toon dat $u$ werk te veel energie verbruik of dat u geen sin en betekenis in $\mathbf{u}$ werk of $u$ lewe vind nie.

- Indien u spiere gespanne is, vra hulle ontspanning of oefening.

- Indien $\mathrm{u}$ voortdurend meer wil rook, alkohol of kalmeermiddels wil gebruik, is dit 'n aanduiding dat u sisteem oorlaai is.

- Lei 'n gebalanseerde lewe. Daar moet 'n balans wees tussen die energie wat $u$ in die arbeidsfeer en die lewe buite die werksfeer aanwend.

- Werk - stel u prioriteite en doelstellings, korttermyn langtermyn.

- Rus - 'n naweek weg en gereelde vakansies.

- Vryetydsbesteding:

lees ten minste een goeie boek per maand;

neem deel aan kulturele aktiwiteite;

onthaal $u$ vriende en familie.

- Ruim tyd in vir 'n dekompressie periode na $\mathbf{u}$ werk waar $\mathrm{u}$ stil kan wees, mediteer, ontspan of oefen, na musiek luister, ensovoorts.

- Gebruik spanningsveiligheidskleppe.

- Indien u werk vir u geen uitdaging inhou nie, doen iets wat 'n uitdaging inhou.
- Indien u werk u emosioneel dreineer en intense konsentrasie en aandag verg, verlig dit deur byvoorbeeld 'n fisies-uitputtende spel te speel.

- Beoefen ontspanningstegnieke, sit of lê gemaklik, trek spiere saam en ontspan, laat $u$ gedagtes saamwerk.

- Bederf uself 'n bietjie, gaan byvoorbeeld 'n aand uit of 'n naweek weg sonder die kinders. Koop 'n nuwe rok of 'n pak klere.

- Raak betrokke - 'n vervelige werk of houding is 'n potensiële bron van spanning:

gebruik u verbeelding en skeppende vermoëns;

bring vernuwing in u werk, huis of u voorkoms;

indien $u$ ander moet lei, motiveer en rig, moet $u$ self persoonlik groei en selfverwesenliking ervaar.

(Mclean 1979; Pines et al, 1981. Freudenberger, Richelson en Pradley, 1981).

- Die keuse van die vrou of as beroepsvrou ò as huisvrou moet positief benader word. Die vrou het nie nodig om skuldig daaroor te voel nie, die keuse is hare. Die belangrikste is dat sy haar ewewig op haar veelsydige lewensweg moet behou. Die lied van Spreuke oor die vrou (Spr. 31:10.31) is waardevol.

Wie sal 'n deugsame vrou vind? want haar waarde is ver bo korale. Die hart van haar man vertrou op haar,

en aan wins sal dit hom nie ontbreek nie.

Sy maak nie net dekens en winterstruie vir haar gesin nie, maar let ook op haar eie persoon en maak vir haar 'n smaakvolle tabberd van fyn linne en van koningspurper vir deftige geleenthede.

Sy gaan veral ook nie sit om haar middeljare/oorgangsjare te beween nie. Sy strek haar hande uit en hou haar gedagtes besig. Sy steek haar hande uit ver buite die mure van haar eie huis.

In die lig van Spreuke 31 sien ons ook die veelsydigheid van die vrou as skepsel van God. Die moeder is onmisbaar, haar waarde is ver bo korale. Maar as haar kinders selfstandig geword het, waarom sal sy nie haar hande buite haar huis uitsteek nie (Jansen 1980: 36 - 39)?

- In die laaste instansie word kortliks verwys na 'n positiewe arbeidsbeskouing.

Die mens is geroepe tot arbeid, dit is deel van die opdrag van God en nie 'n swaar las wat hom te beurt geval het nie. Sy arbeid is roepingsvervulling.

God gee gawes en talente aan die mens. Die ontplooiing van Gods skepping is afhanklik van die arbeid van die mens. Die mens staan met arbeid in die diens van God.

Die verhouding tot arbeid is egter deur die sondeval versteur. Arbeid het 'n moeitevolle karakter verkry. Dit vra inspanning om heerskappy uit te oefen. Ons kry arbeidsoorskatting - 'n verslawing aan werk, waar sommige mense hulle wil doodwerk. Aan die ander kant word onderskatting ook gekry waar sommige arbeidsku geword het. Albei die uiterstes moet vermy word, dit dra tot uitbranding by.

Ons moet ons diepe afhanklikheid van die seën van die Here in ons arbeid besef.

Dit vind gestalte in die vertroue op God in die gebed. Die verhouding van arbeid en rus is hier ter sprake. Die arbeidsetos het sy oorsprong in die rusetos.

Ons moet onthou dat beroepsroeping nie die enigste roeping is nie; ons moet waak om nie so daarin op te gaan dat die ander roepinge nie vervul kan word nie. Ons is eerstens geroep tot die Koninkryk van God, dit is die primêre en oorkoepelende roeping waaruit sekondêre roepinge voortvloei, byvoorbeeld as vader/moeder, burger van die land, lidmaat van die kerk, en as beroepswerker (Duvenage et al. 1976)

\section{VERWYSINGS}

1. Duvenage, B. Die opbou van 'n etiese infrastruknur in die gesondheidsdiensse. PU vir CHO. Referaat.

2. Duvenage B. Es Al. Roeping en werklikheid. Potchef stroom. 1976.

3. Freudenberger, H.J.; Richelson, Geraldine. Burnout The high cost of high achievement. What it is - and how to survive. Ancor USA 1980.

4. Janson, M. Vroue uit die Bybel. Perskor Johannesburg 1980

5. McLean, A.A. Workstress. Addison - Wesley California 1979.

6. Pines, Ayala M. et al. Burnour, from tedium to personal growth. Free Press New York 1981

7. Veninga, R.L.; Spradley, J.P. The work/stress connection: how to cope with job burnout. Little, Brown and Company Bosion 1981 